occurred especially in those patients who discontinued TNFi early in pregnancy and with axial involvement. When resumed during pregnancy, TNFi was able to control the disease. At preconception counselling, the continuation of TNFi during pregnancy should be considered to ensure a better control of disease.

References:

[1] Fischer-Betz R et al.Arthritis Rheumatol. 2015; 67.

Disclosure of Interests: : None declared

DOI: 10.1136/annrheumdis-2020-eular.4695

\section{SAT0369 \\ SPINAL RADIOGRAPHIC PROGRESSION IN EARLY SPONDYLOARTHRITIS: SIX-YEAR RESULTS FROM THE ESPERANZA COHORT}

E. De Miguel $^{1}$, J. F. Garcia Llorente ${ }^{2}$, C. Urrego-Laurín ${ }^{3}$, M. L. GarcíaVivar $^{4}$, C. Fernández-Carballido ${ }^{5}$, M. D. C. Castro Villegas ${ }^{6}$, B. JovenIbáñez ${ }^{6}$, X. Juanola-Roura ${ }^{7}$, C. Tornero ${ }^{1}$, E. Galindez ${ }^{8}$ on behalf of Esperanza Working Group. ${ }^{1}$ Hospital Universitario La Paz, Rheumatology, Madrid, Spain; ${ }^{2}$ Hospital de Galdakao, Rheumatology, Bilbao, Spain; ${ }^{3}$ Hospital Universitario Moncloa, Rheumatology, Madrid, Spain; ${ }^{4}$ Hospital Universitario Basurto, Rheumatology, Bilbao, Spain; ${ }^{5}$ Hospital Universitario Reina Sofía, Rheumatology, Madrid, Spain; ${ }^{6}$ Hospital Universitario Reina Sofía, Rheumatology, Córdoba, Spain; ${ }^{7}$ Hospital Universitario de Bellvitge, Rheumatology, Barcelona, Spain; ${ }^{8}$ Hospital Universitario de Basurto, Rheumatology, Bilbao, Spain

Background: There are few studies focused on the development of structural damage over time in patients with early SpA

Objectives: The aim of this study is to analyze the mSASSS radiographic progression of spine in patients with early spondyloarthritis (SpA) in the Esperanza cohort.

Methods: In this longitudinal study, 49 patients of the Spanish early spondyloarthritis (SpA) Esperanza cohort were included. Every patient had a baseline and a six years lateral X-Ray of the cervical and lumbar of spine. The assessment of spine structural damage was done by the modified Stoke Ankylosing Spondylitis Spine Score (mSASSS). Nine readers, blinded for the diagnosis, participated in the reliability exercise, all of them experienced rheumatologists and members of the Spanish spondyloarthritis working group (GRESSER). The mSASSS progression and development of new syndesmophytes was analyzed. The gold standard of every elemental lesion of the mSASSS and the total mSASSS score was the agreement achieved by the independent categorical opinion of at least five of the nine readers. For reliability, intraclass correlation coefficient (ICC) twoway mixed, absolute agreement was used.

Results: Forty-nine patients were included, $69 \%$ were males and $49 \%$, HLA B27 positive. Mean \pm SD baseline ESR, CRP, BASDAI, BASFI and mSASSS were $10.7 \pm 11.7,5.4 \pm 7.1,3.7 \pm 2.5,2.1 \pm 2.0$ and $0.326 \pm 0.85$, respectively. Interreader ICC reliability of the 9 readers was $0.812(\mathrm{Cl} 95 \% ; 0.764-0.857)$. The mSASSS score at the six-year visit was $0.67 \pm 1.6$ : thirty-nine patients did not present any changes in this score at the end of the follow-up, two patients had $\Delta$ mSASSS of -1 and eight patients, an increase in this score (four patients, +1 ; three patients, +2 and one patient, +9 points).

At baseline, five patients presented one syndesmophyte; at the six-year visit, seven had one syndesmophyte; one patient, two syndesmophytes and another one, one bone bridge. Only $2 / 5$ patients (40\%) with syndesmophytes at baseline showed an increase in $\Delta$ mSASSS; the two patients with a $\Delta$ mSASSS of -1 did not have syndesmophytes at baseline. Five out of eight patients $(62.5 \%)$ with an increase of the $\Delta$ mSASSS presented this lesion at the six-year visit but only two of them showed syndesmophytes at baseline. On the other hand, two of the three patients who showed an increase of the $\Delta$ mSASSS without syndesmophytes at baseline presented an erosion in the anterior vertebral corner and the patient with the bone bridge had a previous syndesmophyte. Our results indicate that in early SpA much of the progression appears in patients without previous syndesmophytes.

Conclusion: Spinal radiographic progression was very low in our early SpA cohort, with a mean progression of 0.3 mSASSS units. Only eight patients $(16.3 \%)$ presented spinal structural progression, most of them not showing syndesmophytes at baseline. It is reasonable to consider that an early diagnosis and monitoring could result in a low radiographic progression.

Disclosure of Interests: Eugenio de Miguel Grant/research support from: Yes (Abbvie, Novartis, Pfizer), Consultant of: Yes (Abbvie, Novartis, Pfizer), Paid instructor for: yes (AbbVie, Novartis, Pfizer, MSD, BMS, UCB, Roche, Grunental, Janssen, Sanofi), Speakers bureau: yes (AbbVie, Novartis, Pfizer, MSD, BMS, UCB, Roche, Grunental, Janssen, Sanofi), Jose Francisco Garcia LLorente: None declared, Claudia Urrego-Laurín: None declared, Maria Luz García-Vivar: None declared, Cristina Fernández-Carballido Consultant of: Yes, I have received fees for scientific advice (Abbvie, Celgene, Janssen, Lilly and Novartis), Speakers bureau: Yes, I have received fees as a speaker (Abbvie, Celgene, Janssen, Lilly, MSD, Novartis), María del Carmen Castro Villegas: None declared Beatriz Joven-Ibáñez Speakers bureau: Abbvie, Celgene, Janssen, Merck Sharp \& Dohme, Novartis, Pfizer, Xavier Juanola-Roura: None declared, Carolina Tornero: None declared, E. Galindez: None declared DOI: 10.1136/annrheumdis-2020-eular.5501

\begin{tabular}{|l|l}
\hline SAT0370 & TUMOUR NECROSIS FACTOR INHIBITOR \\
& THERAPY DOES NOT REDUCE THE INCIDENCE \\
& OF COMORBIDITIES AND EXTRA-ARTICULAR \\
& MANIFESTATIONS IN ANKYLOSING SPONDYLITIS: \\
& AN ANALYSIS OF THREE US CLAIMS DATABASES
\end{tabular}

A. Deodhar ${ }^{1}$, K. Winthrop ${ }^{1}$, R. Bohn², B. Chan ${ }^{1}$, R. Suruki ${ }^{2}$, J. Stark $^{3}$, H. Yun ${ }^{4}$, S. Siegel ${ }^{1}$, L. Chen ${ }^{4}$, J. Curtis ${ }^{4} .{ }^{1}$ Oregon Health \& Science University, Portland, United States of America; ${ }^{2}$ UCB Pharma, Raleigh, United States of America; ${ }^{3}$ UCB Pharma, Smyrna, United States of America; ${ }^{4}$ University of Alabama at Birmingham, Birmingham, United States of America

Background: Comorbidities and extra-articular manifestations (EAMs) substantially increase disease burden and mortality risk in patients (pts) with ankylosing spondylitis (AS) ${ }^{1,2}$ Tumour necrosis factor inhibitors (TNFi) are highly efficacious and effective in AS treatment (tx), and are used after inadequate response to non-steroidal anti-inflammatory drugs. ${ }^{3,4}$ However, the impact of TNFi on the incidence of comorbidities and EAMs in pts with AS is unknown. ${ }^{5}$

Objectives: To determine the incidence of comorbidities and EAMs in TNFi vs non-TNFi treated pts with AS in the US.

Methods: This was a retrospective, observational cohort study using data from 3 healthcare insurance claims databases: Multi-Payer Claims Database (MPCD Optum Insight; 2007-2010), Truven MarketScan ${ }^{\circledR}$ (2010-2014) and US Medicare Fee-for-Service Claims database (2006-2014). Eligible pts: $\geq 20$ years (yrs) for MarketScan/MPCD or $\geq 65$ yrs for Medicare, had an AS diagnosis ( $\geq 2$ International Classification of Disease, $9^{\text {th }}$ version [ICD-9] diagnosis codes of 720.0 from a rheumatologist) and $\geq 12$ months' continuous medical and pharmacy enrolment prior to AS diagnosis (AS index date). Pts with AS not receiving $t x$ were excluded. Tx exposure was reported from the first date of a new prescription/administration of an AS tx (no prior exposure) after the AS index date. Crude incidence rates (IR; shown as cases/100 pt-yrs) were calculated for EAMs (uveitis, psoriasis [PSO], psoriatic arthritis [PsA], inflammatory bowel disease [IBD]), with follow-up until the earliest of: death, lost medical/ pharmacy coverage, study period end, first outcome occurrence, tx switch/discontinuation. Hazard ratios (HRs) of comorbidities (hospitalised infection, solid cancers) and EAMs for propensity score (PS)-matched pt groups were calculated using Cox proportional hazard regression models. Pts with the specific comorbidity/EAM of interest prior to AS index date were excluded. PS analyses assessed probability of TNFi initiation vs non-TNFi tx and adjusted for factors including comorbidities and demographics. HRs with confidence intervals crossing 1 are not reported.

Results: 20,460 pts with AS were eligible (MPCD: 2,384; MarketScan: 9,032; Medicare: 9,044). In all databases, crude IR of EAMs were higher for TNFi vs non-TNFi treated pts (Figure 1). In the PS-matched cohort, incidences of hospitalised infections were lower in TNFi vs non-TNFi treated pts from the MarketScan and Medicare databases (Figure 2). Higher incidences of solid cancers and EAMs were observed in TNFi vs non-TNFi treated pts; Medicare data (Figure 2). A higher risk of PsA and PSO was seen in TNFi vs non-TNFi treated pts; MarketScan data (Figure 2). PS-matched cohort data from the MPCD database were non-significant.

Conclusion: Despite strong efficacy in treating AS-related signs and symptoms, similar incidence of comorbidities and increased incidence of some EAMs (IBD, $\mathrm{PSO} / \mathrm{PsA}$, uveitis) was seen in TNFi vs non-TNFi treated pts in the PS-matched analyses. This may be due to channelling of pts with more severe AS to receive TNFi, despite the PS-matched analysis aiming to overcome this. Moreover, prior medical history of Medicare pts may not be captured in the database, as pts are typically older with longer disease durations. While these results confirm previous findings, ${ }^{6}$ a prospective observational study is required to generalise to pts outside the US

References:

[1] Stolwijk C. Ann Rheum Dis 2015;74:1373-8;

[2] Bremander A. Arthritis Care Res 2011;63:550-6;

[3] Braun J. Scand J Rheumatol 2005;34:178-90;

[4] Ji X. Front Pharmacol 2019;10:1476;

[5] Maxwell LJ. Cochrane Database Syst Rev 2015:CD005468;

[6] Walsh J. J Pharm Health Serv Res 2018;9:115-21. 
Figure 1. Crude incidence of EAMs by treatment exposure in patients with AS using TNFi and without TNFi treatment ( $95 \%$ Cls included)

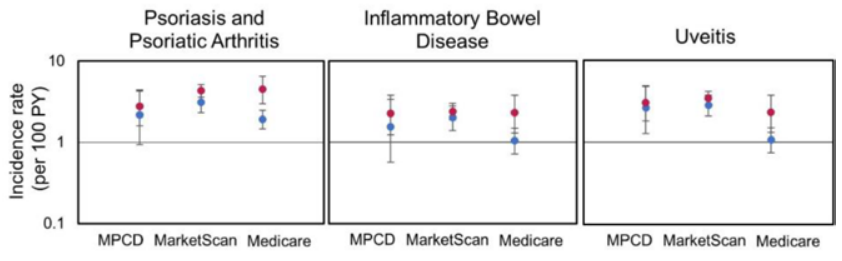

$\bullet$ TNFi $\bullet$ Without TNF

AS: ankylosing spondyloarthritis; $\mathrm{Cl}$ : confidence interval; EAM: extra-articular manifestation; MPCD: Multi-Payer Claims Database; PY: patient-years; TNFi: tumour necrosis factor inhibitor.

Figure 2. Propensity score-weighted hazard ratios of comorbidities and EAMs by treatment exposure in patients with $\mathrm{AS}$ using $\mathrm{TNFi}$ and without TNFi treatment

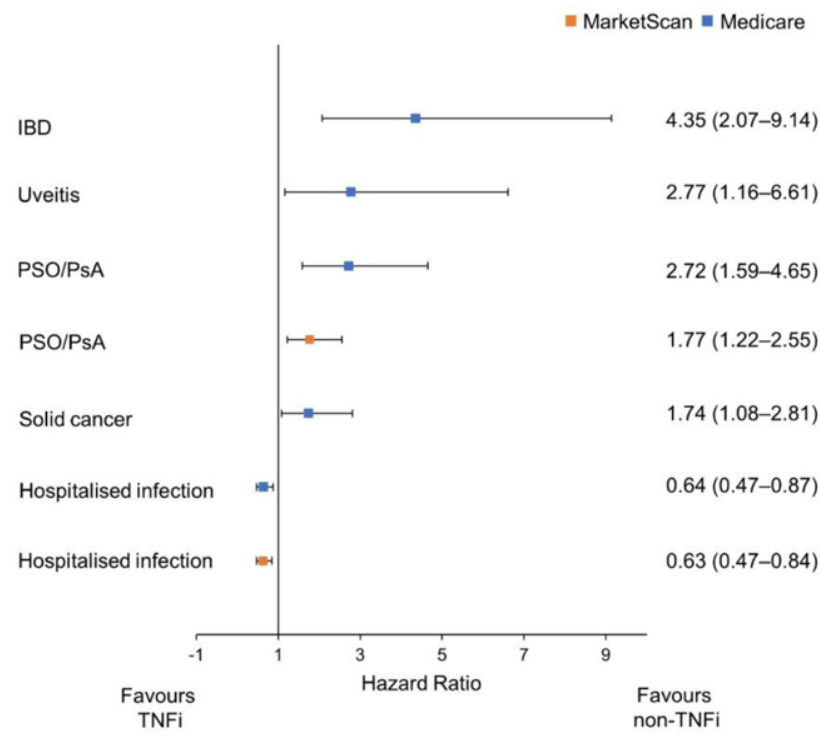

The forest plot shows propensity score-weighted hazard ratios and $95 \% \mathrm{Cls}$. Some data have been excluded due to a lack of events recorded in the dataset. All propensity scoreweighted hazard ratios with $\mathrm{Cls}$ crossing one were deemed non-significant and were therefore not included; this includes all relevant data from the MPCD database. AS: ankylosing spondylitis; CI: confidence interval; EAM: extra-articular manifestation; IBD: inflammatory bowel disease; MPCD: Multi-Payer Claims Database; PsA: psoriatic arthritis; PSO: psoriasis; TNFi: tumour necrosis factor inhibitor.

Acknowledgments: This study was funded by UCB Pharma. Editorial services were provided by Costello Medical.

Disclosure of Interests: Atul Deodhar Grant/research support from: AbbVie, Eli Lilly, GSK, Novartis, Pfizer, UCB, Consultant of: AbbVie, Amgen, Boehringer Ingelheim, Bristol Myer Squibb (BMS), Eli Lilly, GSK, Janssen, Novartis, Pfizer, UCB, Speakers bureau: AbbVie, Amgen, Boehringer Ingelheim, Bristol Myer Squibb (BMS), Eli Lilly, GSK, Janssen, Novartis, Pfizer, UCB, Kevin Winthrop Grant/research support from: Bristol-Myers Squibb, Consultant of: AbbVie, Bristol-Myers Squibb, Eli Lilly, Galapagos, Gilead, GSK, Pfizer Inc, Roche, UCB, Rhonda Bohn Consultant of: UCB Pharma, Benjamin Chan: None declared, Robert Suruki Employee of: UCB Pharma, Jeffrey Stark Employee of: UCB Pharma, Huifeng Yun Grant/research support from: Bristol-Myers Squibb and Pfizer, Sarah Siegel: None declared, Lang Chen: None declared, Jeffrey Curtis Grant/research support from: AbbVie, Amgen, Bristol-Myers Squibb, Corona, Crescendo, Genentech, Janssen, Pfizer, Roche and UCB Pharma, Consultant of: AbbVie, Amgen, Bristol-Myers Squibb, Corona, Crescendo, Genentech, Janssen, Pfizer, Roche and UCB Pharma

DOI: 10.1136/annrheumdis-2020-eular.4201

SAT0371

ARE ENGLISH-LANGUAGE VIDEOS ON YOUTUBE A USEFUL SOURCE OF INFORMATION FOR SPONDYLOARTHRITIS?

S. Elangovan ${ }^{1}$, Y. H. Kwan ${ }^{2}$, W. Fong ${ }^{1,3,4} .{ }^{1}$ Singapore General Hospital, Rheumatology and Immunology, Singapore, Singapore; ${ }^{2}$ Duke-NUS Medical
School, Program in Health Services and Systems Research, Singapore, Singapore; ${ }^{3}$ Duke-NUS Medical School, Singapore, Singapore; ${ }^{4}$ National University of Singapore, Yong Loo Lin School of Medicine, Singapore, Singapore

Background: Spondyloarthritis ( $\mathrm{SpA})$ is a family of chronic inflammatory disorders. Social media, such as YouTube, is a popular online platform where patients often visit for information. However, the validity of the content uploaded onto YouTube is not known.

Objectives: This study aimed to evaluate the content, reliability and quality of the most viewed English-language YouTube videos on SpA.

Methods: Keywords "spondyloarthritis", "spondyloarthropathy" and "ankylosing spondylitis" were searched on YouTube on October $7^{\text {th }}, 2019$. The top 270 videos were screened. Videos were excluded if they were irrelevant, in non-English language or if they had no audio. Total number of views, duration on YouTube (days), video length, upload date, number of likes, dislikes, subscribers and comments were recorded for videos. A modified 5-point DISCERN tool ${ }^{1}$ and the 5-point Global Quality Scale (GQS) score ${ }^{2}$ were used to assess the reliability and quality of the videos, with higher scores indicating greater reliability and quality respectively.

Results: Two hundred of 270 videos were included in the final analysis [ $61.5 \%$ from healthcare professionals, $37.0 \%$ from patients, $1.5 \%$ from news channels]. Of the 200 videos, 15 were uploaded within the last year and 112 in the last five years. $120(60 \%)$ were categorized as useful information (Group 1), $6(3 \%)$ as misleading information (Group 2), $52(26 \%)$ as useful patient opinion (Group 3 ) and $22(11 \%)$ as misleading patient opinion (Group 4). Useful videos were mainly from healthcare professionals or patients $(86 \%)$. Useful videos (Group 1 and 3) had higher median (IQR) number of subscribers [2700 (14700) vs 211 (457), $p<0.01$ ], reliability scores [3 (1) vs $2(1), p<0.01$ ] and GQS scores [3 (1) vs. 2 (1), p < 0.001] compared to misleading videos (Group 2 and 4), respectively.

Videos uploaded by healthcare professionals tended to have more useful information [94\% (116 of 123) vs. $66 \%$ (49 of 74 ), $p<0.001]$ and had higher median (IQR) reliability scores [3 (1) vs $2(1), p<0.001]$ and GQS scores [3 (2) vs $2(1), p<0.001$ ] compared to patient uploaded videos respectively. Of the 5 (out of 123) videos from healthcare professionals that had misleading information, it was because of outdated information on diagnosis ( 3 videos) and treatment ( 5 videos) of SpA. Of the 22 videos that had misleading patient opinion, 9 (41\%) wrongly described the clinical features for SpA and $14(64 \%)$ portrayed the current evidence based treatment options as ineffective and described alternative treatment plans (i.e. diet restrictions, complementary and alternative medicine).

Conclusion: The majority of English language YouTube videos have useful information on the topic of SpA, however, $31 \%$ of patient opinions have inaccurate information on the clinical features and treatment options, and viewers need to be cognisant of these "fake news".

References:

[1] Charnock D, Shepperd S, Needham G, Gann R (1999) DISCERN: an instrument for judging the quality of written consumer health information on treatment choices. J Epidemiol Community Health 53(2): 105-111

[2] Bernard A, Langille M, Hughes S, Rose C, Leddin D, Veldhuyzen van Zanten $S$ (2007) A systematic review of patient inflammatory bowel disease information resources on the World Wide Web. Am J Gastroenterol 102(9):2070-2077 Disclosure of Interests: Sakktivel Elangovan: None declared, Yu Heng Kwan: None declared, Warren Fong Consultant of: Abbvie, Janssen, Novartis, Speakers bureau: Abbvie, Janssen, Novartis

DOI: 10.1136/annrheumdis-2020-eular.3109

\begin{tabular}{|l|l}
\hline SAT0372 & PATIENTS WITH PSORIATIC ARTHRITIS SHOW \\
HIGHER BONE DENSITY COMPARED TO AGE AND \\
GENDER MATCHED PATIENTS WITH ANKYLOSING \\
SPONDYLITIS
\end{tabular}

D. Freier ${ }^{1}$, E. Wiebe ${ }^{1}$, R. Biesen ${ }^{1}$, T. Buttgereit ${ }^{2}$, S. Hermann ${ }^{1}$, T. Gaber ${ }^{1}$, F. Buttgereit ${ }^{1}{ }^{1}$ Charité - Universitätsmedizin Berlin, Department of Rheumatology and Clinical Immunology, Berlin, Germany; ${ }^{2}$ CharitéUniversitätsmedizin Berlin, Department of Dermatology and Allergy, Berlin, Germany

Background: The prevalence of osteoporosis in inflammatory rheumatic diseases such as psoriatic arthritis (PsA) has not been sufficiently clarified yet, and the data in the literature are heterogeneous. In addition, it is still unclear to what extent patients with PsA differ in terms of bone density from patients with other forms of spondyloarthritis such as ankylosing spondylitis (AS).

Objectives: In an interim analysis of the Rh-GIOP Study (ClinicalTrials.gov Identifier NCT02719314), we observed that PsA patients demonstrated more frequently normal bone density than any other patient group analyzed (suffering from e.g. rheumatoid arthritis or systemic sclerosis). The main objective of this investigation was to compare bone density data from patients with PsA and 